\title{
Resolving Conflicts by a Random Device*
}

\author{
Erik O. Kimbrough ${ }^{a}$, Roman M. Sheremeta ${ }^{b}$, and Timothy Shields ${ }^{b}$ \\ a Department of Economics (AE1), School of Business and Economics, Maastricht University, \\ P.O. Box 616, 6200 MD Maastricht, The Netherlands \\ ${ }^{b}$ Argyros School of Business and Economics, Chapman University, \\ One University Drive, Orange, CA 92866, USA
}

September 7, 2011

\begin{abstract}
We examine conflict resolution via a random device. We model conflict as a two-agent rent-seeking contest for a fixed prize. Before conflict arises, both agents may agree to allocate the prize by coin flip to avoid the costs of conflict. In equilibrium, risk-neutral agents with relatively symmetric conflict capabilities agree to resolve the conflict by randomization. However, with sufficiently asymmetric capabilities, conflicts are unavoidable because the stronger agent prefers to fight. Laboratory experiments confirm that the availability of the random device partially eliminates conflicts when agents are relatively symmetric; however, the device also reduces conflict between substantially asymmetric agents.
\end{abstract}

JEL Classifications: C72, C91, D72

Keywords: contest, conflict resolution, experiments

Corresponding author: Roman M. Sheremeta, sheremet@chapman.edu

* For financial support, the authors thank the Economic Science Institute at Chapman University. For insightful comments, the authors thank Larry lannaccone, Kai Konrad, Florian Morath, Jared Rubin and economic seminar participants at the Economic Science Institute at Chapman University and Max Planck Institute in Munich. Any remaining errors are the authors' own. 


\section{Introduction}

In archaic Greece, representatives from powerful city-states would travel to remote Delphi to consult the Oracle housed at a temple dedicated to the god Apollo. The Oracle, a priestess believed to be possessed by Apollo, provided advice to visitors about controversial political matters by responding to questions that typically could be answered with a "yes" or "no" response, and owing partly to the Oracle's divine connection, the city-states would abide by its counsel (Bowden, 2005). lannaccone et al. (2011) argue that the purpose of the Oracle, as well as other forms of institutionalized divination, was to resolve problematic and potentially costly disputes through a multilateral commitment to the outcome of a randomization device.

Consider a (hypothetical) dispute between Athens and Sparta over a piece of territory, where the alternative to abiding by the Oracle's proposed allocation is armed conflict. In this context, adherence to the decision of the Oracle constitutes a surplus-preserving solution to a multi-player contest where agents (city-states) are relatively equally powerful. With relatively equal opponents, the potential cost of conflict may overwhelm the gains to deviation from the Oracle's decision. Hence, the small and autonomous city-states have a strong interest in supporting a randomizing Oracle.

Historically mechanisms of divination took many forms, including divining rods, the casting of lots, and the inspired interpretation of cracks in fire-heated bones or of ominous patterns observed in other media ranging from freshly spread entrails to wafting smoke (Bernstein, 1996; Bowden, 2005). Regardless of the mechanism, willingness to submit to its 
outcome can be viewed as a strategic choice to avoid potentially costly conflict. ${ }^{1}$ More familiar examples of conflict resolution via random device are abundant. Rock-paper-scissors, drawing straws, and throwing dice settle many friendly disputes, like who gets to sit in the front seat on a road trip, or who gets the top bunk bed in a dorm room.

However, even today the stakes can be high: Recently, a judge in Florida required lawyers on opposing sides of a case to settle a disagreement by rock-paper-scissors, and the auction houses of Sotheby's and Christie's played the game to determine who would receive a contract to sell $\$ 17.8$ million worth of art. $^{2}$ In some political jurisdictions, a coin flip decides the outcome of elections in which two candidates receive equal numbers of votes, and in other jurisdictions coin flips are employed to determine the recipient of a government contract when two companies tender equal offers (Lissau, 2011). Similarly, conflicting parties frequently consent to third-party arbitration (Burgess et al., 1996; Szymanski, 2003) in order to avoid the costs of going to court.

Returning to our example, consider a situation in which the power of Sparta is ascendant and that of Athens on the decline. When Sparta grows sufficiently strong, it no longer benefits from commitment to a random device. If the gains to conflict are sufficient, then random decisions by the Oracle can only handcuff Sparta's ambition. ${ }^{3}$ Although it is clear why the random device may work as a surplus-preserving commitment mechanism, it is not

\footnotetext{
${ }^{1}$ Another well-known historical example of commitment to what might be considered a random device is the battlefield agreement to settle a conflict by single combat between two renowned warriors. Such combat is attested in myth (e.g., combat described in the lliad between Menelaus and Paris and between Achilles and Hector) and numerous historical wars (e.g., the Battle of Clastidium 222 BC, the Battle of Badr 624 AD, the Battle of the Trench 627 AD, to name a few). Similarly, Leeson (2010) describes the medieval mechanism of "trial by battle" through which uncertain property rights were frequently assigned.

${ }^{2}$ See the following news article from the AP: http://www.msnbc.msn.com/id/13221673/ns/us_news-weird_news/

${ }^{3}$ Indeed, as Greece became a unified empire it no longer had need of the Delphic Oracle for political purposes. As such by the third century BCE the Oracle was used mainly for religious and personal inquiries (Bowden 2005).
} 
obvious why agents, committed ex ante to the result of the coin flip, would follow through on such a commitment after observing an ex post unfavorable decision by the random device. One way to ensure that agents follow the commitment can be through binding contracts, such as the Sotheby's rock-paper-scissors example. In such a case, agents could sign a contract ex ante that would commit them ex post to follow the result of the random device. A similar mechanism is employed in the aforementioned election and contract assignment rules (Lissau, 2011).

However, agents cannot always enter binding contracts. As in our historical example, it is unclear what would prevent Athens from rejecting the Oracle's counsel and fighting Sparta anyway if Sparta was favored by the decision. Two reasons why agents committed to the Oracle's decisions in ancient times were (1) historical context and the perceived 'mystical' nature of such decisions (lannaccone et al., 2011), and (2) reputational concerns resulting from repeated interaction with one another and with the Oracle (Dellarocas, 2006). Similar reputational factors may be at work in some of the lighthearted examples of commitment to randomization we described above. Whether commitment to the random device mechanism is binding or non-binding, such mechanisms are prevalent in daily life and are often employed in modern economics, politics and law.

Motivated by historical awe-inspiring examples and modern mundane practices, we theoretically and experimentally examine individual willingness to resolve conflicts by commitment to a random device. We alter both the availability of a random device and the relative strength of players in four treatments where we model conflict as a variation of the classic Tullock (1980) rent-seeking contest between two agents. In our setup, two agents face 
the prospect of a conflict over a valuable prize. Before the conflict arises both participants may agree to settle the dispute by flipping a coin (an Oracle) and thereby avoiding the costs of the contest. We show analytically that if agents are relatively symmetric, then conflicts will be avoided through appeals to the Oracle. However, when agents are substantially asymmetric then conflicts are unavoidable because the stronger agent has no incentive to consent to randomization. In laboratory experiments subject behavior is largely consistent with the predictions: the introduction of a random commitment device reduces conflict, and the reduction is significantly greater (though not complete) when agents are more symmetric. Thus, although the costs of conflict are not always avoided when the theory predicts that they will be, they are nevertheless frequently avoided when theory predicts that they will not.

The rest of the paper is organized as follows: in section 2, we briefly review the literature on conflicts and conflict resolution; in section 3 we detail our theoretical results; section 4 describes our experimental design, procedures and hypotheses; section 5 analyzes the results of the experimental sessions; and section 6 concludes.

\section{Background}

A rich literature on conflict resolution in economics extends back to Schelling's (1960) Strategy of Conflict in which he applied the tools of game theory to identify the necessity of credible commitment to avoiding conflict. Since Schelling, economists and others have developed numerous models of conflict, all of which highlight the resources wasted when conflict occurs (Konrad, 2009). One of the best-known conflict models is the rent-seeking 
contest, first developed by Tullock (1980) and elaborated by Skaperdas (1996), in which agents expend resources to increase their probabilities of winning a valuable prize. An agent's probability of winning equals his expenditure divided by the sum of all contestants' expenditures, so an agent who expends more resources has a better chance of receiving the prize. In equilibrium, all agents make positive expenditures; however, from the point of view of society, all such expenditures are wasteful. Moreover, laboratory experiments testing this model indicate that in practice the costs of conflict are even higher than predicted by the theory (Davis and Reilly, 1998; Potters et al., 1998; Fonseca, 2009; Sheremeta and Zhang, 2010; Mago et al., 2011; Morgan et al., 2011; Sheremeta, 2011).

Given the high costs of conflict both in theory and practice, a number of mechanisms for inducing commitment have been proposed, ranging from deterrence via extensive armament (Schelling, 1960) and hostage exchange (Williamson, 1985) to contractually binding sidepayments (Charness et al., 2007; Schoonbeek, 2009; Kimbrough and Sheremeta, 2011). The common property of all such conflict resolution mechanisms is that they seek to alter payoffs in a way that eliminates the incentive for one party to unilaterally initiate conflict. In general, any mechanism that provides all potential combatants with an expected payoff at least as large as their expected payoff from conflict is preferable to outright conflict. Hence, in a dispute over an indivisible resource, random assignment, or assignment by means of an "uncorrelated asymmetry", that is, some asymmetry between players that is uncorrelated with their probabilities of winning a conflict, e.g. first possession (see Maynard-Smith, 1982), can be supported as a Nash equilibrium. 
Here we explore the decision to employ a random device (hereafter the Oracle) to avoid costly conflict in a Tullock contest. Prior to the conflict, both parties can elect to bind themselves to the decision of the Oracle. If both parties elect to adhere to the Oracle, then the contest prize is awarded randomly and no conflict ensues. Otherwise, if one or both of the parties elect not to use the Oracle, then the two parties engage in a Tullock contest to assign the prize.

\section{The Oracle Model}

Consider a game of potential conflict between two risk-neutral players for a prize valued at $v$ by both players. We define the game in two sequential stages, the Oracle stage and the conflict stage. In the Oracle stage, players 1 and 2 simultaneously decide whether to resolve the conflict by flipping a fair coin or to enter the conflict stage. ${ }^{4}$ If both players agree to the coin flip, then the game ends with neither player advancing to the conflict stage. The prize is allocated to each player with probability $p_{1}^{\text {Oracle }}=p_{2}^{\text {Oracle }}=0.5$, and players 1 and 2 receive the expected payoffs of $E\left(\pi_{1}^{\text {Oracle }}\right)=E\left(\pi_{2}^{\text {Oracle }}\right)=v / 2$. However, if either player refuses to abide by the outcome of the coin flip, then both players advance to the conflict stage.

In the conflict stage, both players make irreversible effort expenditures $e_{1}$ and $e_{2}$ to increase their probabilities of receiving the prize. Players have different conflict capabilities (strengths) $a_{i}\left(a_{1}>a_{2}\right)$, so that the stronger player 1 can expend the same effort, yet have a higher chance of winning the prize. Specifically, player i's probability of winning is defined by the following contest success function (Skaperdas, 1996):

\footnotetext{
${ }^{4}$ The model can be easily extended to an unfair coin, i.e. $p_{1}^{\text {Oracle }} \neq p_{2}{ }^{\text {Oracle }}$.
} 


$$
p_{i}\left(e_{1}, e_{2}\right)=a_{i} e_{i} /\left(a_{1} e_{1}+a_{2} e_{2}\right) .
$$

The expected payoff for player $i$ is equal to the probability of player $i$ winning, $p_{i}\left(e_{1}, e_{2}\right)$, times the prize valuation, $v$, minus contest expenditure, $e_{i}$ :

$$
E\left(\pi_{i}\right)=p_{i}\left(e_{1}, e_{2}\right) v-e_{i}
$$

By differentiating (2) and solving the best response functions simultaneously, we obtain unique Nash equilibrium effort expenditure levels for players 1 and 2:

$$
e_{1}^{*}=v a_{1} a_{2} /\left(a_{1}+a_{2}\right)^{2} \text { and } e_{2}^{*}=v a_{1} a_{2} /\left(a_{1}+a_{2}\right)^{2} .
$$

Given the equilibrium effort expenditures (3), the probabilities of winning the contest by players 1 and 2 are:

$$
p_{1}^{*}=a_{1} /\left(a_{1}+a_{2}\right) \text { and } p_{2}^{*}=a_{2} /\left(a_{1}+a_{2}\right) .
$$

The expected payoffs of players 1 and 2 in the equilibrium are:

$$
E\left(\pi_{1}{ }^{*}\right)=v a_{1}{ }^{2} /\left(a_{1}+a_{2}\right)^{2} \text { and } E\left(\pi_{2}^{*}\right)=v a_{2}{ }^{2} /\left(a_{1}+a_{2}\right)^{2} \text {. }
$$

Hence, the contest is both individually costly to the loser and socially costly because all conflict stage expenditures are wasted. As a result, if both players possess complete knowledge of the game's structure and incentives, they may prefer to avoid the conflict stage by consulting the Oracle (flipping the coin). ${ }^{5}$ In fact, the weaker player 2 will always choose the Oracle over the conflict, since his expected payoff in the case of conflict is lower than in the case of a coin flip, i.e. $E\left(\pi_{2}{ }^{*}\right)=v a_{2}{ }^{2} /\left(a_{1}+a_{2}\right)^{2}<v a_{2}{ }^{2} /\left(a_{2}+a_{2}\right)^{2}=v / 4<v / 2=E\left(\pi_{2}{ }^{\text {Oracle }}\right)$. However, the choice of player 1 crucially depends on how much stronger player 1 is than player 2. In particular, player 1 will choose the coin flip only if $E\left(\pi_{1}{ }^{*}\right)=v a_{1}^{2} /\left(a_{1}+a_{2}\right)^{2} \leq v / 2=E\left(\pi_{1}^{\text {Oracle }}\right)$, or when $a_{2} \geq(\mathrm{v} 2-1) a_{1}$.

\footnotetext{
${ }^{5}$ One can interpret the Oracle stage as players bargaining to determine the form of the contest success function, i.e. either completely noisy or lottery contest success function.
} 
Hence, our theory predicts that if players' capabilities are relatively symmetric, then conflicts will be avoided through appeals to the Oracle. ${ }^{6}$ However, when the asymmetry is substantial then conflicts are unavoidable because the stronger party will always choose to enter the conflict. Note that if we increase the probability that the Oracle assigns the prize to the stronger player, i.e. $p_{1}^{\text {Oracle }}>p_{2}^{\text {Oracle }}$, we can again create an Oracle that both players would prefer over conflict. Indeed, because a randomization device is always surplus-preserving, there exists an Oracle that would be preferred by both players for any costly conflict situation. Even if the Oracle itself is costly to setup or to maintain, it is preferable by both players as long as individual costs of creating and maintaining the Oracle are less than individual benefits of avoiding conflicts through the Oracle, i.e. $c_{1} \leq E\left(\pi_{1}^{\text {oracle }}\right)-E\left(\pi_{1}{ }^{\text {conflict }}\right)$ and $c_{2} \leq E\left(\pi_{2}^{\text {oracle }}\right)$ $E\left(\pi_{2}{ }^{\text {Conflict }}\right)$. In what follows we explore the simplest case in which the Oracle allocates the prize by flipping a fair coin $\left(p_{1}^{\text {Oracle }}=p_{2}^{\text {Oracle }}=0.5\right)$ and there are no costs of maintaining the Oracle $\left(c_{1}\right.$ $=c_{2}=0$.

\section{Experimental Design and Procedures}

We employ four treatments to test the predictions of our theory: Baseline-Unbalanced, Baseline-Balanced, Oracle-Unbalanced, and Oracle-Balanced, where Unbalanced and Balanced refer to the relative strengths of players 1 and 2 . The outline of the experimental design and the

\footnotetext{
${ }^{6}$ In the relatively symmetric case, i.e. $a_{2} \geq(\sqrt{ } 2-1) a_{1}$, there is also a subgame perfect Nash equilibrium in which both players simultaneously choose not to use the Oracle. Since the use of Oracle requires unilateral agreement, if one player chooses not to use the Oracle then the other player might as well choose not to use it. However, it easy to see that such subgame perfect Nash equilibrium is not strategically stable (Kohlberg and Mertens, 1986), and both players can benefit from unilaterally deviating from it. In fact, we do not find any support for this equilibrium in our data, as weak players almost always choose to use the Oracle.
} 
theoretical predictions for each treatment are shown in Table 1. In all treatments subjects compete for a prize with value $v=100$. In the Baseline-Unbalanced treatment, players 1 and 2 have substantially different strengths, i.e. $a_{1}=4$ and $a_{2}=1$. In equilibrium, the expenditures of players 1 and 2 are $e_{1}{ }^{*}=16$ and $e_{2}{ }^{*}=16$, the probabilities of winning are ${p_{1}}^{*}=0.8$ and $p_{2}{ }^{*}=0.2$, and the expected payoffs are $E\left(\pi_{1}{ }^{*}\right)=64$ and $E\left(\pi_{2}{ }^{*}\right)=4$. In the Baseline-Balanced treatment, players 1 and 2 have relatively symmetric strengths, i.e. $a_{1}=3 / 2$ and $a_{2}=1$. In equilibrium players 1 and 2 expend $e_{1}{ }^{*}=24$ and $e_{2}{ }^{*}=24$, win the conflict with probabilities $p_{1}{ }^{*}=0.6$ and $p_{2}{ }^{*}$ $=0.4$, and earn expected payoffs of $E\left(\pi_{1}{ }^{*}\right)=36$ and $E\left(\pi_{2}{ }^{*}\right)=16$. Thus, the costs of conflict are increasing in the relative symmetry of the players. ${ }^{7}$

The other two treatments, Oracle-Unbalanced and Oracle-Balanced introduce the Oracle stage to the game, prior to the conflict stage. In the Oracle stage, players simultaneously decide whether to flip a coin in order to determine the winner of the prize. In case of disagreement or joint refusal to consult the Oracle, both treatments are equivalent to BaselineUnbalanced and Baseline-Balanced treatments. The equilibrium prediction in the OracleUnbalanced treatment is that conflict always occurs, because the stronger player 1 always chooses to enter the conflict since $E\left(\pi_{1}{ }^{*}\right)=64>50=E\left(\pi_{1}{ }^{\text {Oracle }}\right)$. On the other hand, in the Oracle-Balanced treatment, conflict never occurs, because both players always agree to consult the Oracle since $E\left(\pi_{1}^{*}\right)=36<50=E\left(\pi_{1}^{\text {Oracle }}\right)$.

Each experimental session consisted of 30 periods of a single treatment. Subjects were randomly assigned the initial role of either player 1 or player 2 , and each player 1 was matched with a player 2 . Subjects remained in this role and matched pair for the first 15 periods of the

\footnotetext{
${ }^{7}$ This result has long been recognized in the theoretical literature (Baik, 1994; Konrad, 2009).
} 
session. Then all players 1 became players 2 and vice versa, and subjects were re-matched into new pairs in which they remained for the final 15 periods. $^{8}$ Each period, in the BaselineUnbalanced and Baseline-Balanced treatments subjects chose their expenditures, any number between 0 and 100, in order to increase the probability of winning the prize of 100 francs. At the end of each period, the computer displayed these expenditures, as well as corresponding payoffs. In the Oracle-Unbalanced and Oracle-Balanced treatments, subjects first made their decisions whether to flip a computerized coin in order to determine who would receive the prize, or to enter the second stage conflict. ${ }^{9}$ The computer displayed subjects' first stage decisions. Then, if at least one of the paired players decided not to flip the coin, subjects proceeded to the second stage where they chose their expenditures. At the end of each period, the computer displayed individual decisions, as well as corresponding payoffs, to each subject.

After 30 periods, subjects also participated in a one period contest in which they could expend resources to win a prize worth zero. This was done to elicit subjects' non-monetary value of winning. At the end of each experimental session, subjects completed a brief demographic survey. To reinforce the one-shot incentives of the game, subjects knew beforehand that we would randomly select 4 of the 30 periods for payment. At the end of the session, subjects' total earnings from these 4 periods less their expenditures for the zero value prize were added to or subtracted from an initial endowment of 500 francs (which we described as a participation fee). We converted francs to USD at a rate of $25=\$ 1$, and subjects

\footnotetext{
${ }^{8}$ This type of matching protocol was used to mitigate concerns about fairness and inequality among subjects. Also, we wanted for subjects to have sufficient experience in each role before switching to another role. Finally, we wanted to preserve contamination of subjects' behavior in one session by outliers (alternatively, in a random matching environment the presence of several outliers could substantially impact the behavior of all subjects in the session).

${ }^{9}$ One could also design an experiment to study non-binding Oracle agreements, where in a repeated-game setting the loser may refuse to abide by the coin flip and instead engage in conflict.
} 
were paid privately in cash and dismissed from the experiment. Sessions lasted approximately an hour each.

180 subjects were recruited at random from the subject pool consisting of graduate and undergraduate students at a private university in the United States. Subjects were randomly assigned into 8 experimental sessions ( 2 per treatment) with between 20 and 24 subjects each. Subjects sat at, and interacted via, visually isolated computer terminals, and instructions were read aloud by the experimenter as subjects followed along on paper. The experiments were programmed using z-Tree (Fischbacher, 2007). Before participating subjects took a quiz (nonincentivized) to confirm their understanding of the experimental procedures. Subjects received their initial endowments for arriving to the experiment on time and received their earnings in cash privately at the end of each session. The average experimental earnings, including the $\$ 20$ participation fee, were $\$ 24.5$, ranging from a low of $\$ 11.4$ to a high of $\$ 35.6$. No subject participated more than once, and no subject had prior experience with a similar experimental environment. Instructions for the Oracle-Unbalanced treatment are included in an appendix. Instructions for the other treatments are available upon request.

\section{Results}

\subsection{The Impact of the Oracle on Surplus}

The main research question of our study is whether the availability of the Oracle reduces the cost of conflict and increases economic surplus. Table 2 displays summary statistics for all four treatments. Comparing surpluses in Table 2, we find that surplus is $39 \%$ higher in the 
Oracle-Unbalanced than the Baseline-Unbalanced treatment (76.1 versus 54.8 ), and it is $69 \%$ higher in the Oracle-Balanced than the Baseline-Balanced treatment (75.8 versus 44.9). To support this finding statistically, we estimate panel regressions separately for each of the Unbalanced and Balanced treatments where the dependent variable is pairwise surplus, defined as $v-\left(e_{1}+e_{2}\right)$ for each pair in each period, and the independent variables are a period trend, a dummy-variable controlling for the last 15 periods after players switch roles, and a dummy-variable for the presence of the Oracle. We include a random effects error structure for the individual subjects to account for repeated measures, which is equivalent to group random effects since surplus is measured at the level of the pair.

The estimation results are shown in Table 3. Mixed evidence on the significance of the period trend indicates increasing surplus over time in the Unbalanced treatment, though not in the Balanced treatment. ${ }^{10}$ The insignificant estimated effect of switching roles reveals the absence of notable re-matching effects.

More important for our purposes, regressions (1) and (2) indicate that the effect of the Oracle treatment on surplus is positive and significant for both treatments ( $p$-values $<0.01$ ). However, relative to theoretical benchmarks, surplus in the Oracle-Unbalanced treatment is significantly higher than predicted (76.1 versus 68 ); while in the Oracle-Balanced treatment, it is significantly lower than predicted (75.8 versus 100$).{ }^{11}$ We summarize these findings in Result 1.

\footnotetext{
${ }^{10}$ As we discuss further in Section 5.3, increasing surplus over time comes primarily from a decrease in strong player conflict expenditures over time.

11 Separately for Oracle-Unbalanced and Oracle-Balanced treatments, we estimate random effects panel regressions in which the dependent variable is surplus and the independent variables are a constant, a period trend, and a dummy-variable controlling for switched roles. Wald test indicates that the estimated constant, capturing surplus, is significantly higher than predicted in the Oracle-Unbalanced treatment $(p$-value $=0.02)$ and significantly lower than predicted in the Oracle-Balanced treatment ( $p$-value $<0.001$ ).
} 
Result 1: The Oracle increases mean surplus in both treatments. However, the surplus is significantly higher than predicted in the Oracle-Unbalanced treatment and significantly lower in the Oracle-Balanced treatment.

Does the deviation from the theory derive from the entry decisions in the Oracle stage or from expenditures in the conflict stage? The estimations of regressions (3) and (4) in Table 3 provide the first insight. These regressions use only those observations which resulted in conflict. The estimated effect of the Oracle treatment is insignificant for both the Unbalanced and Balanced treatments, indicating that higher surplus in the Oracle treatments mainly comes from decisions not to enter the conflict; when conflict occurs in the Oracle treatments, it is neither more nor less intense than conflict in the Baseline treatments. In the next section we further analyze how entry decisions differ from theoretical predictions, therefore implicitly shaping Result 1.

\subsection{Probability of a Conflict}

The primary source of deviations between observed and predicted surplus in result (1) is deviation from the predicted frequency of appeals to the Oracle to settle conflicts. In particular, Table 2 reports that subjects in the Oracle-Balanced treatment employ the randomization device with probability 0.63 , although the theory predicts that no conflict will occur. On the other hand, the Oracle-Unbalanced subjects appeal to the Oracle with probability 0.40 , though theory predicts that they will fight with probability 1 . Figure 1 displays time series of conflict entry probability by subject type, all of which are relatively stable over time. When conflict occurs, the stronger player usually instigates, and the probability of entry by strong players is 
higher in the Oracle-Unbalanced than the Oracle-Balanced treatment. Furthermore, most weaker players choose not to enter conflict, regardless of their relative strength.

To support these observations, we estimate panel probit models with random effects for each subject, where the dependent variable takes a value of 1 if a player chose to engage in conflict and 0 otherwise. The independent variables are a constant term, a dummy-variable for the weaker player 2, a period trend, and a dummy-variable controlling for switched roles after period 15. Table 4 reports estimation results. Insignificant estimated coefficients of the period trend and the role-switching dummy indicate no notable changes over time or as a result of rematching. ${ }^{12}$ Consistent with the comparative statics predictions of the model, the weaker player 2 chooses to engage in a conflict significantly less often than the stronger player 1. However, as noted above, the overall probability of a conflict is lower than the predicted value of 1 in the Oracle-Unbalanced treatment and higher than 0 in the Oracle-Balanced treatment $(p \text {-values }<0.01)^{13}$. Table 4 reports an additional estimation combining data from the OracleUnbalanced and Oracle-Balanced treatments (column 3). Again consistent with the comparative statics predictions, the Unbalanced coefficient is positive, indicating that the probability of a conflict increases in players' asymmetry. We summarize these findings in Result 2.

\footnotetext{
${ }^{12}$ These observations are generally robust to estimating the effects separately for each type. The slight upward trend in the entry probability of stronger players in the Unbalanced treatment is weakly significant ( $p$-value $=$ 0.07).

${ }^{13}$ To test these hypotheses, we estimate two linear probability panel regressions where the dependent variable takes a value of 1 if a conflict occurred (i.e. if one or both members of the pair chose conflict) and a value of 0 otherwise. The dependent variables include a period trend and a dummy for the last 15 periods and we include group specific random effects to control for repeated observations. Wald tests reject the hypothesized values of the constant term. Regression output is unreported but available from the authors upon request.
} 
Result 2: The probability of a conflict is higher when players are more asymmetric. There are significantly fewer conflicts than predicted in the Oracle-Unbalanced treatment and significantly more conflicts in the Oracle-Balanced treatment.

These findings support our claim that the divergence between the observed and predicted impact of the Oracle on surplus in both treatments (Result 1) can largely be traced to differences between the observed and predicted probabilities of conflict (Result 2). There are several potential explanations for why we observe "too little" conflict in the Oracle-Unbalanced and "too much" conflict in the Oracle-Balanced treatment. First and most importantly, the predicted probabilities of conflict are at the boundaries, so that in the Oracle-Unbalanced treatment even one non-equilibrium choice of non-entry implies the average probability of conflict less than one. ${ }^{14}$ Similarly, in the Oracle-Balanced treatment even one non-equilibrium choice of entry implies the average probability of conflict more than zero. Thus, deviations from the predictions can only be observed in one direction.

In addition, one could offer preference-based explanations of our observations. For example, if subjects care about the (expected) payoffs of others, both inequality aversion (Fehr and Schmidt, 1999; Bolton and Ockenfels, 2000) and preferences for social efficiency (Charness and Rabin, 2002) imply a lower expected probability of conflict. Given the strength asymmetry in the Oracle-Unbalanced treatment, and the inequality of expected payoffs between stronger and weaker players, inequality aversion would imply a diminished probability of entry by stronger players (which we observe in our data). The expected effect of inequality aversion would be smaller in the Oracle-Balanced treatment.

\footnotetext{
${ }^{14}$ The problem of boundary equilibrium predictions has been well recognized in linear public good experiments, where the Nash equilibrium is to contribute nothing. For a review see Laury and Holt (2008).
} 
Finally, it is also possible that some subjects are driven by "joy of winning" (Parco et al. 2005; Sheremeta, 2010) and/or spite (Herrmann and Orzen, 2008). If subjects' entry decisions are driven by joy of winning, then they should be more likely to enter the contest in general. ${ }^{15}$ If subjects are spiteful, they may seek to maximize payoff difference by reducing opponents' payoffs (Leininger, 2003; Hehenkamp et al., 2004). In the Oracle-Balanced treatment, the only way for the stronger player to reduce the weaker player's payoff is by entering a conflict. On the other hand, by design, payoff difference in the Oracle-Unbalanced treatment is already very large, and thus the returns to additional spite are likely to be diminished by the already substantial inequality of expected payoffs in equilibrium.

Whether inequality aversion, spite, joy of winning, or some other factors produce deviations of individual entry decisions from point predictions, the comparative statics of the Oracle model hold in our experiment, suggesting that commitment to a random device can serve as an effective conflict resolution mechanism. This is encouraging, given that many earlier experiments have documented very high costs of conflict (cf. Section 2 above). Indeed, the same pattern emerges in our experiment. As we show in the next section, when conflict occurs, the costs exceed the predictions of the theory.

\footnotetext{
${ }^{15}$ Following Sheremeta (2010), after 30 periods of play, we elicited "joy of winning" by letting subjects make expenditures in a conflict over a prize worth nothing. A novel feature of our design is that in the OracleUnbalanced and Oracle-Balanced treatments, subjects first make entry decisions, and then, upon entry into the conflict stage, they choose their expenditure level. Thus, we can test whether joy of winning explains decisions to enter the conflict. For that reason, we re-estimated models in Table 4, including joy of winning as an additional independent variable. The estimation results are available from the authors upon request. When combining the data for both treatments the joy of winning increases the probability of entry. However it appears to affect subject types differently in different treatments. For example, there is a positive correlation between joy of winning and entry for weaker players in both treatments, but for stronger players the correlation is positive in the Balanced treatment and negative in the Unbalanced treatment. Since our experiment was not designed to study the joy of winning, we are hesitant to draw any strong conclusions. Future research should carefully examine whether expenditures for the prize of zero measure the desire to compete or the desire to win, or possibly both.
} 


\subsection{Expenditures}

Table 2 reports mean expenditures in excess of the Nash equilibrium predictions for both player types in all treatments, and Figure 2, which displays time series of mean individual expenditure by role and treatment, also shows that the excess expenditures persist throughout the experiment.

To examine the determinants of expenditures, we combine the data across treatments and estimate a single panel regression in which the dependent variable is expenditure and the independent variables are a dummy-variable for the weaker player 2 , a period trend, a dummyvariable for the last 15 periods indicating the periods after roles have switched, Unbalanced and Oracle treatment dummies, and a constant term. For the Oracle-Balanced and OracleUnbalanced treatments we restrict analysis to instances of conflict. As before, we include a random effects error structure for the individual subjects to account for repeated measures.

Table 5 displays the output of this regression. As in the other regressions, the estimated coefficients of the period trend and the role-switching dummy are insignificant, suggesting that this finding is robust. ${ }^{16}$ Consistent with the theory, expenditures decrease as players become more asymmetric (the coefficient on Unbalanced is negative and significant), and an insignificant coefficient on the Weaker player dummy-variable indicates no significant differences in expenditures between stronger players 1 and weaker players $2 .^{17}$ One might expect that the forgone opportunity to avoid the costs of conflict would induce retaliatory

\footnotetext{
${ }^{16}$ However, if we include a separate period trend for each type, we find that stronger players in the Unbalanced treatment reduce their conflict expenditures over time $(p$-value $<0.01)$; this suggests that some learning takes place regarding the effects of relative strength on win probability.

${ }^{17}$ As a robustness check, we have also re-estimated the regression in Table 5 including interactions between Weaker and Unbalanced and between Weaker and Oracle to see whether expenditure of player 1 is different from the expenditure of player 2 in the Unbalanced and/or Oracle treatment. Estimation results are very similar and the interaction dummies are not significant.
} 
behavior by those subjects that chose not to enter but were dragged into conflict by their counterpart. The insignificant effect of the Oracle treatment on conflict expenditures, conditional on entry, indicates that conflict intensity remains unchanged in the presence of the randomization device. ${ }^{18}$ Nevertheless, Wald tests reject the hypotheses that the constant term is equal to 24 (the predicted expenditure in the Balanced treatments) and that the sum of the constant and the Unbalanced dummy-variable is equal to 16 (the predicted expenditure in the Unbalanced treatments) ( $p$-values $<0.01) .{ }^{19}$ We summarize these findings in Result 3.

Result 3: Although subjects overinvest in conflict on average, expenditures of both types are lower when players are more asymmetric. Furthermore, for a given asymmetry level, there is no difference in expenditures between stronger and weaker players.

While our experiment was not designed to test this hypothesis in particular, the data suggest that, ceteris paribus, conflict expenditures decline with relative strength asymmetry in repeated Tullock contests, and this finding is consistent with a wider literature. For example, in animal behavior studies, one common explanation for conflict behavior is based on "fighting assessment" (Parker, 1974). So-called "mutual assessment" models hold that in resource contests, animals assess the relative strength of their opponents, and upon recognizing an unfavorable asymmetry they are less likely to expend resources in conflict, thereby reducing

\footnotetext{
${ }^{18}$ As a robustness check in the Oracle-Balanced and Oracle-Unbalanced treatments, we have also estimated regressions controlling for the individual entry decisions in the Oracle stage. Estimation results are virtually the same. As another robust check, we also re-estimate the regressions using lag variable of whether players engaged in conflict in the past period or not. The effect of the lag is positive, but insignificant, and the other results are unchanged except that the estimated period trend is now negative and significant ( $p$-value $=0.03$ ). All estimation results are available from the authors upon request.

${ }^{19}$ Prior studies have also found "joy of winning" to be a significant explanation for excess conflict expenditures (Parco et al. 2005; Sheremeta 2010; Brookins and Ryvkin, 2010; Mago et al., 2011). We re-estimated Table 5 including joy of winning as an additional independent variable. The results for the main explanatory variables were virtually the same, with the estimated coefficient of joy of winning being positive and significant.
} 
the total costs of conflict. ${ }^{20}$ Empirical evidence from a broad range of species shows that the average length of resource contests is decreasing in the relative asymmetry of the competitors (Arnott and Elwood, 2009). Finally, several recent experimental studies have also documented that increasing players' asymmetry reduces effort expenditures in diverse competitive environments (Fonseca, 2009; Anderson and Freeborn, 2010; DeScioli and Wilson, in press).

\section{Conclusion}

Our model of conflict resolution between asymmetric contestants predicts that when players are sufficiently symmetric, they will choose to settle their disputes by appealing to a randomization device (the Oracle) in order to avoid the costs of conflict. On the other hand, if players are sufficiently asymmetric, the stronger player will always choose outright conflict because the benefits of conflict exceed the expected value of the random allocation. We test the Oracle model in the laboratory with two treatments, one in which the players are relatively Balanced and one in which they are Unbalanced. In keeping with previous studies of conflict we find evidence that conflicts are generally more costly than expected, as conflict expenditures are higher than predicted in all treatments. Also, consistent with previous animal behavior and human subject research on the intensity of conflict with respect to the relative strength asymmetry of the contestants, we find that expenditures are greater in the Balanced than in the Unbalanced treatments. Most importantly, we find compelling evidence that the Oracle reduces the costs of conflict in both treatments: when agents are relatively symmetric, the

\footnotetext{
${ }^{20}$ As the Kenny Rogers lyric famously says, "You gotta know when to hold 'em, know when to fold 'em..."
} 
Oracle increases average surplus by $69 \%$, and when they are relatively asymmetric, it still increases average surplus by $39 \%$.

Our results highlight the power of commitment to a randomization device as a surpluspreserving conflict resolution mechanism and explain both historical and modern implementations ranging from the casting of lots and reading of tea leaves to rock-paperscissors. Many superficially mystifying practices that appear absurd to modern eyes can be revealed to serve similar purposes, and the history of economic and political institutions may benefit from studying such mechanisms in this light.

Both the data and the theory suggest a number of interesting experimental extensions. For example, one could explore how much subjects would be willing to pay (in tribute) to maintain an Oracle; the theoretical willingness to pay is noted in Section 3, but if there exists a threshold for provision of the Oracle as a public good, then the collective action problem may reduce the likelihood of surplus preserving solutions. On the other hand, one could ask whether various side-payment schemes would increase the willingness of strong players to consent to the randomization device, and if subjects can bargain over the Oracle's assignment probabilities, the observed surplus gains may be extended to even more asymmetric environments. 


\section{References}

Anderson, Lisa, and Beth Freeborn. 2010. "Varying the intensity of competition in a multiple prize rent seeking experiment." Public Choice, 143(1), 237-254.

Arnott, Gareth, and Robert W. Elwood. 2009. "Assessment of Fighting Ability in Animal Contests." Animal Behavior, 77, 991-1004.

Baik, Kyung H. (1994). "Effort levels in contests with two asymmetric players." Southern Economic Journal, 61, 367-378.

Bernstein, Peter. 1996. Against the Gods: The Remarkable Story of Risk. New York: John Wiley \& Sons.

Bolton, Gary E. and Axel Ockenfels. 2000. "ERC: A Theory of Equity, Reciprocity, and Competition." American Economic Review, 90(1), 166-193.

Bowden, Hugh. 2005. Classical Athens and the Delphic oracle: divination and democracy. Cambridge; New York : Cambridge University Press.

Brookins, P., and Ryvkin, D. 2010. An experimental study of bidding in contests of incomplete information. Working Paper, Florida State University.

Burgess, Paul L., Marburger, Daniel R., and Scoggins, John F. 1996. "Do Baseball Arbitrators Simply Flip a Coin?" In Baseball Economics, J. Fizel et al eds., Praeger: Westport, CT.

Charness, Gary, and Matthew Rabin. 2002. "Understanding Social Preferences With Simple Tests," Quarterly Journal of Economics, 117(3), 817-869.

Charness, Gary, Guillame R. Frechette, and Cheng-Zong Qin. 2007. "Endogenous Transfers in the Prisoner's Dilemma Game: An Experimental Test of Cooperation and Coordination." Games and Economic Behavior, 60(2), 287-306.

Davis, Douglas, and Robert Reilly. 1998. "Do Many Cooks Always Spoil the Stew? An Experimental Analysis of Rent Seeking and the Role of a Strategic Buyer." Public Choice, 95, 89-115.

Dellarocas, Chris. (2006). "Reputation Mechanisms." Handbooks in Information Systems, Vol. I, Handbook on Economics and Information Systems, edited by Terrence J. Hendershott, Elsevier, 629-660.

DeScioli, Peter, and Bart J. Wilson. 2011. "The Territorial Foundations of Human Property," Evolution and Human Behavior, In Press.

Ernst, Fehr, and Klaus M. Schmidt. 1999. "A Theory Of Fairness, Competition, And Cooperation." Quarterly Journal of Economics, 114(3): 817-868.

Fischbacher, Urs. 2007. z-Tree: Zurich Toolbox for Ready-Made Economic Experiments, Experimental Economics, 10, 171-178.

Fonseca, Miguel A. 2009. "An experimental investigation of asymmetric contests." International Journal of Industrial Organization. 27(5), 582-591.

Hehenkamp, Burkhard, Wolfgang Leininger, and Alex Possajennikov. 2003. "Evolutionary Equilibrium in Tullock Contests: Spite and Overdissipation." European Journal of Political Economy, 20, 1045-1057.

Herrmann, Benedikt, and Henrik Orzen. 2008. "The appearance of homo rivalis: Social preferences and the nature of rent seeking," Working Paper, University of Nottingham. 
Iannaccone, Laurence R., Colleen E. Haight, Jared Rubin, 2011. "Lessons from Delphi: Religious markets and spiritual capitals", Journal of Economic Behavior \& Organization, 77(3), 326338.

Kimbrough, Erik O., and Roman M. Sheremeta. 2011. “Make Him an Offer He Can't Refuse: Avoiding Conflicts through Side-Payments," Economic Science Institute Working Paper, Chapman University, Orange.

Kohlberg, Elon, and Mertens, Jean-Francois (1986). On the Strategic Stability of Equilibria. Econometrica, 54, 1003-1037.

Konrad, Kai. A. 2009. Strategy and Dynamics in Contests. New York, NY: Oxford University Press. Laury, Susan K., and Charles A. Holt. 2008. "Voluntary provision of public goods: Experimental results with interior Nash Equilibria." In C. R. Plott \& V. L. Smith (Eds.), Handbook of experimental economics results. (Vol. 1) 792-801. New York: Elsevier.

Leeson, Peter. 2011. "Trial by Battle," Journal of Legal Analysis, 3, 341-375.

Leininger, Wolfgang. 2003. "On evolutionarily stable behavior in contests." Economics of Governance, 4(3), 177-186.

Lissau, Russell. 2011. Coin flips choose winners in Island Lake, Green Oaks. Daily Herald. http://www.dailyherald.com

Mago, Shakun D., Anya C. Savikhin, and Roman M. Sheremeta. 2011. "Facing Your Opponents: Social Recognition and Information Feedback in Contests." Working Paper, University of Chicago.

Maynard-Smith, John. 1982. Evolution and the Theory of Games. Cambridge, UK: Cambridge Unviersity Press.

Morgan, John, Henrik Orzen, and Martin Sefton. 2011. Endogenous Entry in Contests. Economic Theory, forthcoming.

Parco, J., Rapoport, A., and Amaldoss, W., 2005. Two-stage contests with budget constraints: An experimental study. Journal of Mathematical Psychology, 49, 320-338.

Parker, G.A. 1974. "Assessment Strategy and the Evolution of Fighting Behavior," Journal of Theoretical Biology, 47, 223-243.

Potters, Jan C. Casper G. De Vries, and Frans Van Linden. 1998. “An Experimental Examination of Rational Rent Seeking." European Journal of Political Economy, 14, 783-800.

Schelling, Thomas. 1960. The Strategy of Conflict. Cambridge, MA: Harvard University Press.

Schoonbeek, Lambeert. 2009. "Bribing Potential Entrants in a Rent-Seeking Contest," Public Choice, 139(1-2), 153-158.

Sheremeta, Roman M. 2010. "Experimental Comparison of Multi-Stage and One-Stage Contests." Games and Economic Behavior, 68(2), 731-747.

Sheremeta, Roman M. 2011. "Contest Design: An Experimental Investigation." Economic Inquiry, 49, 573-590.

Sheremeta, Roman M., and Jingjing Zhang. 2010. "Can Groups Solve the Problem of OverBidding in Contests?" Social Choice and Welfare, 35, 175-197.

Skaperdas, Stergios. 1996. "Contest Success Functions," Economic Theory, 7(2), 283-290.

Szymanski, Stefan. 2003. "The Economic Design of Sporting Contests." Journal of Economic Literature, 41(4), 1137-1187. 
Tullock, Gordon. 1980. "Efficient Rent Seeking." In Toward a Theory of the Rent-seeking Society, ed. James M. Buchanan, Robert D. Tollison, and Gordon Tullock. 97-112. College Station, TX: Texas A\&M University Press.

Williamson, Oliver. 1985. "Credible Commitments: Using Hostages to Support Exchange," American Economic Review, 73(4), 519-540. 


\section{Tables and Figures}

Table 1: Experimental Design and Theoretical Predictions

\begin{tabular}{lccccc}
\hline \hline & \multicolumn{5}{c}{ Treatment } \\
\hline & Player & $\begin{array}{c}\text { Baseline- } \\
\text { Unbalanced }\end{array}$ & $\begin{array}{c}\text { Baseline- } \\
\text { Balanced }\end{array}$ & $\begin{array}{c}\text { Oracle- } \\
\text { Unbalanced }\end{array}$ & $\begin{array}{c}\text { Oracle- } \\
\text { Balanced }\end{array}$ \\
\hline Strength, $a_{i}$ & 1 & 4 & $3 / 2$ & 4 & $3 / 2$ \\
Expenditure, $e_{i}^{*}$ & 2 & 1 & 1 & 1 & 1 \\
\cline { 2 - 6 } & 1 & 16 & 24 & 16 & 24 \\
Probability, $p_{i}^{*}$ & 2 & 16 & 24 & 16 & 24 \\
\cline { 2 - 6 } & 1 & 0.80 & 0.60 & 0.80 & 0.60 \\
Expected Payoff, $E\left(\pi_{i}{ }^{*}\right)$ & 2 & 0.20 & 0.40 & 0.20 & 0.40 \\
\cline { 2 - 6 } & 1 & 64 & 36 & 64 & 36 \\
Individual Probability of & 2 & 4 & 16 & 4 & 16 \\
Choosing Conflict & 1 & $\mathrm{~N} / \mathrm{A}$ & $\mathrm{N} / \mathrm{A}$ & 1.00 & 0.00 \\
Probability of a Conflict & 2 & $\mathrm{~N} / \mathrm{A}$ & $\mathrm{N} / \mathrm{A}$ & 0.00 & 0.00 \\
\cline { 2 - 6 } Surplus & & 1.00 & 1.00 & 1.00 & 0.00 \\
\hline & & 68 & 52 & 68 & 100 \\
\hline
\end{tabular}

Table 2: Average Statistics

\begin{tabular}{|c|c|c|c|c|c|}
\hline & & \multicolumn{4}{|c|}{ Treatment } \\
\hline & Player & $\begin{array}{c}\text { Baseline- } \\
\text { Unbalanced }\end{array}$ & $\begin{array}{l}\text { Baseline- } \\
\text { Balanced }\end{array}$ & $\begin{array}{c}\text { Oracle- } \\
\text { Unbalanced }\end{array}$ & $\begin{array}{c}\text { Oracle- } \\
\text { Balanced }\end{array}$ \\
\hline \multirow[t]{2}{*}{ Expenditure, $e_{i}{ }^{*}$} & 1 & $21.4(0.8)$ & $27.9(0.8)$ & $17.8(0.7)$ & $31.8(1.7)$ \\
\hline & 2 & $23.7(1.1)$ & $27.2(0.9)$ & $19.7(1.2)$ & $28.4(1.8)$ \\
\hline \multirow[t]{2}{*}{ Probability, $p_{i}^{*}$} & 1 & $0.77(0.02)$ & $0.61(0.02)$ & $0.80(0.02)$ & $0.64(0.03)$ \\
\hline & 2 & $0.23(0.02)$ & $0.39(0.02)$ & $0.20(0.02)$ & $0.36(0.03)$ \\
\hline \multirow[t]{2}{*}{ Expected Payoff, $E\left(\pi_{i}^{*}\right)$} & 1 & $55.2(1.7)$ & $33.1(1.8)$ & $61.7(2.1)$ & $32.4(3.1)$ \\
\hline & 2 & $-0.4(1.6)$ & $11.8(1.8)$ & $0.8(1.8)$ & $7.4(2.9)$ \\
\hline \multirow{2}{*}{$\begin{array}{l}\text { Individual Probability of } \\
\text { Choosing Conflict }\end{array}$} & 1 & $\mathrm{~N} / \mathrm{A}$ & $\mathrm{N} / \mathrm{A}$ & $0.60(0.02)$ & $0.33(0.02)$ \\
\hline & 2 & $\mathrm{~N} / \mathrm{A}$ & $\mathrm{N} / \mathrm{A}$ & $0.06(0.01)$ & $0.13(0.01)$ \\
\hline Probability of a Conflict & & 1.00 & 1.00 & $0.63(0.02)$ & $0.40(0.02)$ \\
\hline Surplus & & $54.8(1.5)$ & $44.9(1.4)$ & $76.1(1.2)$ & $75.8(1.6)$ \\
\hline
\end{tabular}

Standard Errors in Parentheses. 
Table 3: The Impact of the Oracle on Group Surplus

\begin{tabular}{lcccc}
\hline \hline \multirow{2}{*}{ Regression } & $(1)$ & $(2)$ & $(3)$ & $(4)$ \\
\hline Dependent Variable & \multicolumn{4}{c}{ Surplus } \\
\cline { 2 - 5 } & Unbalanced & Balanced & Unbalanced & Balanced \\
\hline Period & $0.502^{* *}$ & -0.082 & $0.713^{* * *}$ & -0.243 \\
[period trend] & $(0.163)$ & $(0.175)$ & $(0.179)$ & $(0.182)$ \\
Switch & -3.722 & 5.549 & -3.954 & 4.918 \\
{$[1$ if period $>15]$} & $(5.935)$ & $(6.543)$ & $(6.071)$ & $(8.476)$ \\
Oracle & $21.31^{* * *}$ & $30.96^{* * *}$ & 6.150 & -10.41 \\
[1 if Oracle] & $(5.478)$ & $(5.939)$ & $(5.461)$ & $(8.495)$ \\
Constant & $48.91^{* * *}$ & $43.36^{* * *}$ & $45.76 * * *$ & $46.18^{* * *}$ \\
& $(5.231)$ & $(4.815)$ & $(5.467)$ & $(6.739)$ \\
\hline Observations & 1320 & 1380 & 1090 & 967 \\
Number of groups & 88 & 92 & 86 & 80 \\
\hline
\end{tabular}

*** $p<0.001, * * p<0.01, * p<0.05$.

Robust standard errors in parentheses.

Panel models (1)-(4) include individual subject random effects.

Regressions (3) and (4) use only those observations which resulted in conflict.

Table 4: Individual Probability of Choosing Conflict

\begin{tabular}{lccc}
\hline \hline Regression & $(1)$ & $(2)$ & $(3)$ \\
\hline Dependent Variable & \multicolumn{3}{c}{ Probability of a Conflict } \\
\cline { 2 - 4 } & $\begin{array}{c}\text { Oracle- } \\
\text { Unbalanced }\end{array}$ & $\begin{array}{c}\text { Oracle- } \\
\text { Balanced }\end{array}$ & Oracle \\
\hline Weaker & $-2.002^{* * *}$ & $-1.010^{* * *}$ & $-1.524^{* * *}$ \\
$\quad[1$ if player 2] & $(0.103)$ & $(0.100)$ & $(0.071)$ \\
Period & 0.012 & -0.001 & 0.005 \\
$\quad$ [period trend] & $(0.011)$ & $(0.011)$ & $(0.007)$ \\
Switch & -0.098 & -0.350 & -0.232 \\
$\quad[1$ if period $>15]$ & $(0.189)$ & $(0.188)$ & $(0.132)$ \\
Unbalanced & & & $0.600^{* *}$ \\
$\quad[1$ if Unbalanced] & & & $(0.214)$ \\
Constant & 0.156 & $-0.543^{* *}$ & $-0.464^{* *}$ \\
& $(0.15)$ & $(0.209)$ & $(0.167)$ \\
\hline Observations & 1260 & 1380 & 2640 \\
Number of groups & 42 & 46 & 88 \\
\hline
\end{tabular}

*** $p<0.001,{ }^{* *} p<0.01, * p<0.05$.

Robust standard errors in parentheses.

Panel probit models (1)-(3) include individual subject random effects. 
Table 5: Determinants of Expenditure

\begin{tabular}{lc}
\hline \hline Regression & $(1)$ \\
\hline Dependent Variable & Expenditure \\
\cline { 2 - 2 } Weaker & 0.600 \\
{$[1$ if player 2] } & $(1.450)$ \\
Period & -0.152 \\
[period trend] & $(0.092)$ \\
Switch & -0.682 \\
[1 if period $>15]$ & $(1.879)$ \\
Unbalanced & $-7.753^{* *}$ \\
[1 if Unbalanced] & $(2.483)$ \\
Oracle & -0.569 \\
[1 if Oracle] & $(2.502)$ \\
Constant & $31.351^{* * *}$ \\
& $(2.317)$ \\
\hline Observations & 4114 \\
Number of groups & 177 \\
\hline
\end{tabular}

$* * * \mathrm{p}<0.001, * * \mathrm{p}<0.01, * \mathrm{p}<0.05$.

Robust standard errors in parentheses.

Panel model (1) includes individual subject random effects. 

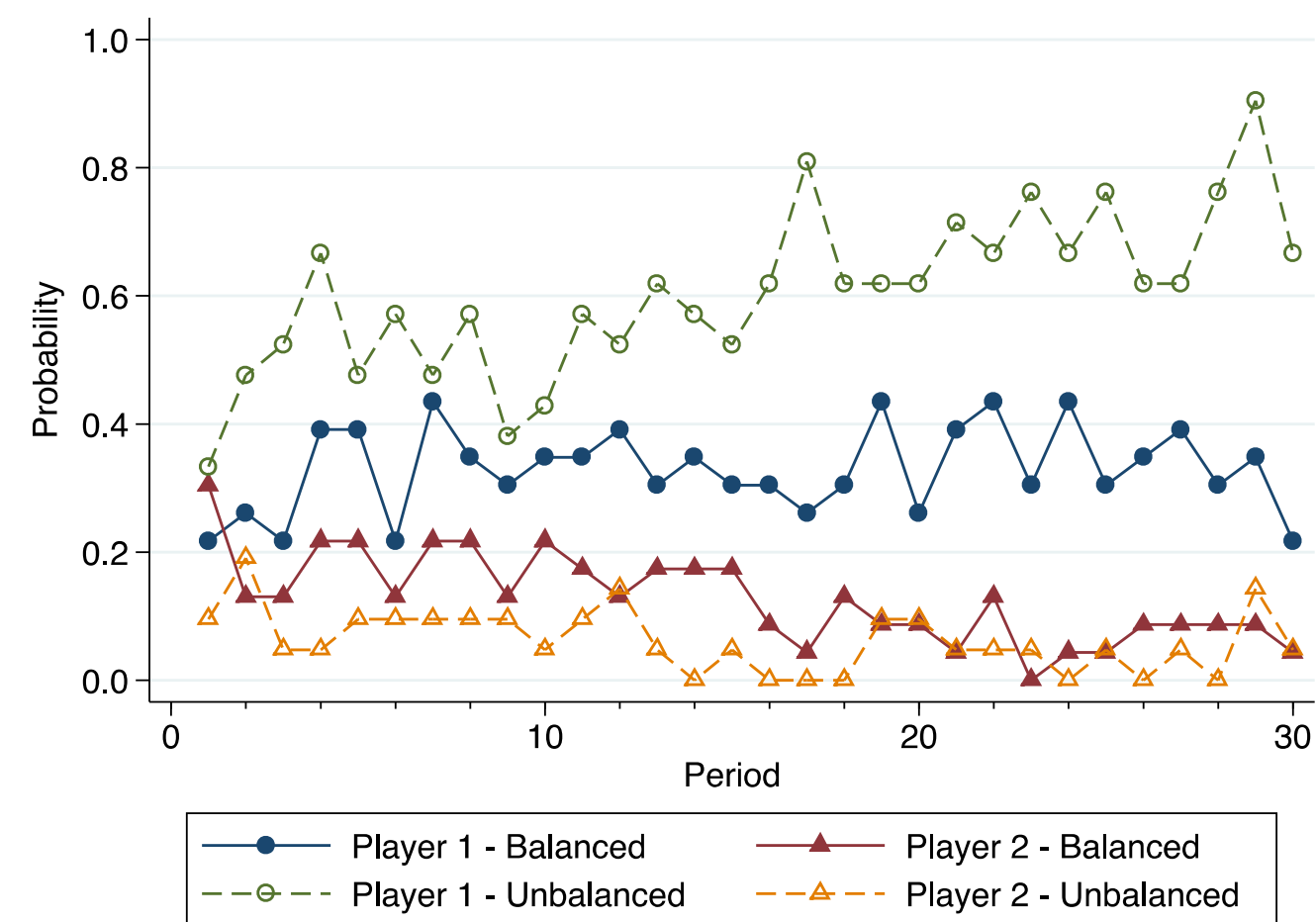

Figure 1: Time Series of Mean Probability of Choosing Conflict by Role, Oracle Treatments

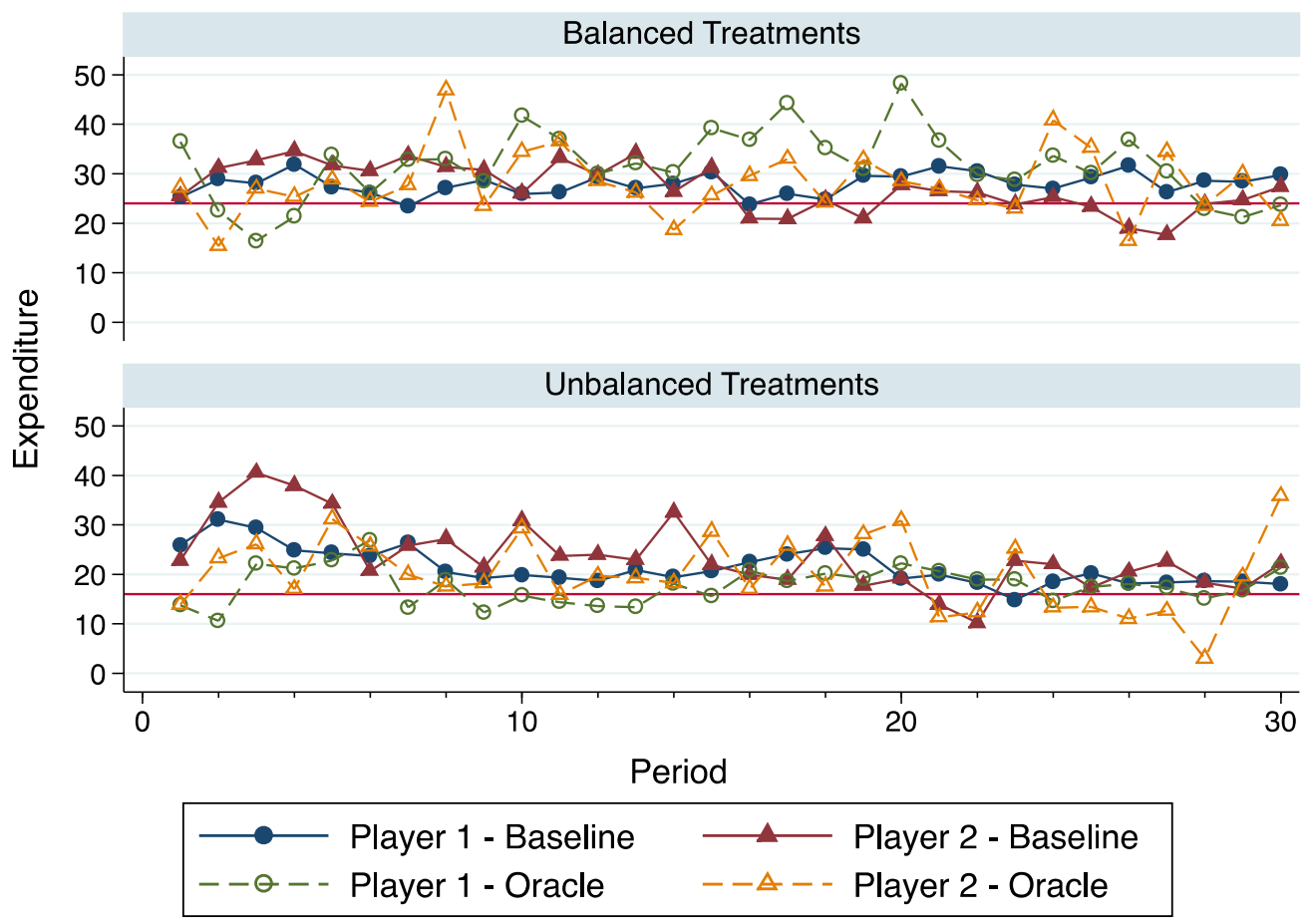

Figure 2: Time Series of Mean Expenditure by Role and Treatment 


\section{Appendix - Instructions for the Oracle-Unbalanced Treatment}

\section{GENERAL INSTRUCTIONS}

This is an experiment in the economics of strategic decision-making. Various research agencies have provided funds for this research. If you follow the instructions closely and make appropriate decisions, you and the other participants in this experiment can earn an appreciable amount of money, which will be paid to you in cash.

The currency used in the experiment is francs. Francs will be converted to U.S. Dollars at a rate of $\mathbf{2 5}$ francs to 1 dollar. You have already earned a $\mathbf{\$ 2 0 . 0 0}$ participation fee (this includes the $\mathbf{\$ 7}$ show up fee). The experiment will consist of $\mathbf{3 0}$ periods and at the end of the experiment we will randomly choose $\mathbf{4}$ of the $\mathbf{3 0}$ periods for actual payment. We will sum your total earnings for these 4 periods and convert them to a U.S. dollar payment.

It is very important that you remain silent and do not look at others' decisions (screens). If you have any questions, or need assistance of any kind, please raise your hand and an experimenter will come to you. If you talk, laugh, exclaim out loud, etc..., you will be asked to leave and you will not be paid. We expect and appreciate you following the laboratory's rules. The remainder of the instructions will describe the decisions you may face in each period.

The participants in today's experiment will be randomly assigned into two-person groups. In addition to the group assignment each participant will also be randomly assigned to a specific type in the group, designated as Person 1 or Person 2. You and the other participant in your group will make choices that will determine your payoffs. The experiment contains 30 rounds. You will remain within the same twoperson group as the same type for 15 rounds. Thereafter you will be regrouped with another participant into a new group where you will be a different type (i.e., if you were Person 1 in the first 15 rounds, you will be Person 2 for the last 15 rounds, and vice-versa).

In each round of the experiment either Person 1 or Person 2 will receive the reward. The reward is worth $\mathbf{1 0 0}$ francs. Each round of the experiment consists of two decision stages. In Stage 1, you and the other person in your group will decide on a specific way to determine who will receive the reward.

\section{YOUR DECISION IN STAGE 1}

In each round, both participants will have the opportunity to choose whether they want to flip a computer coin in order to determine who will receive the reward. An example of your decision screen is shown below. 


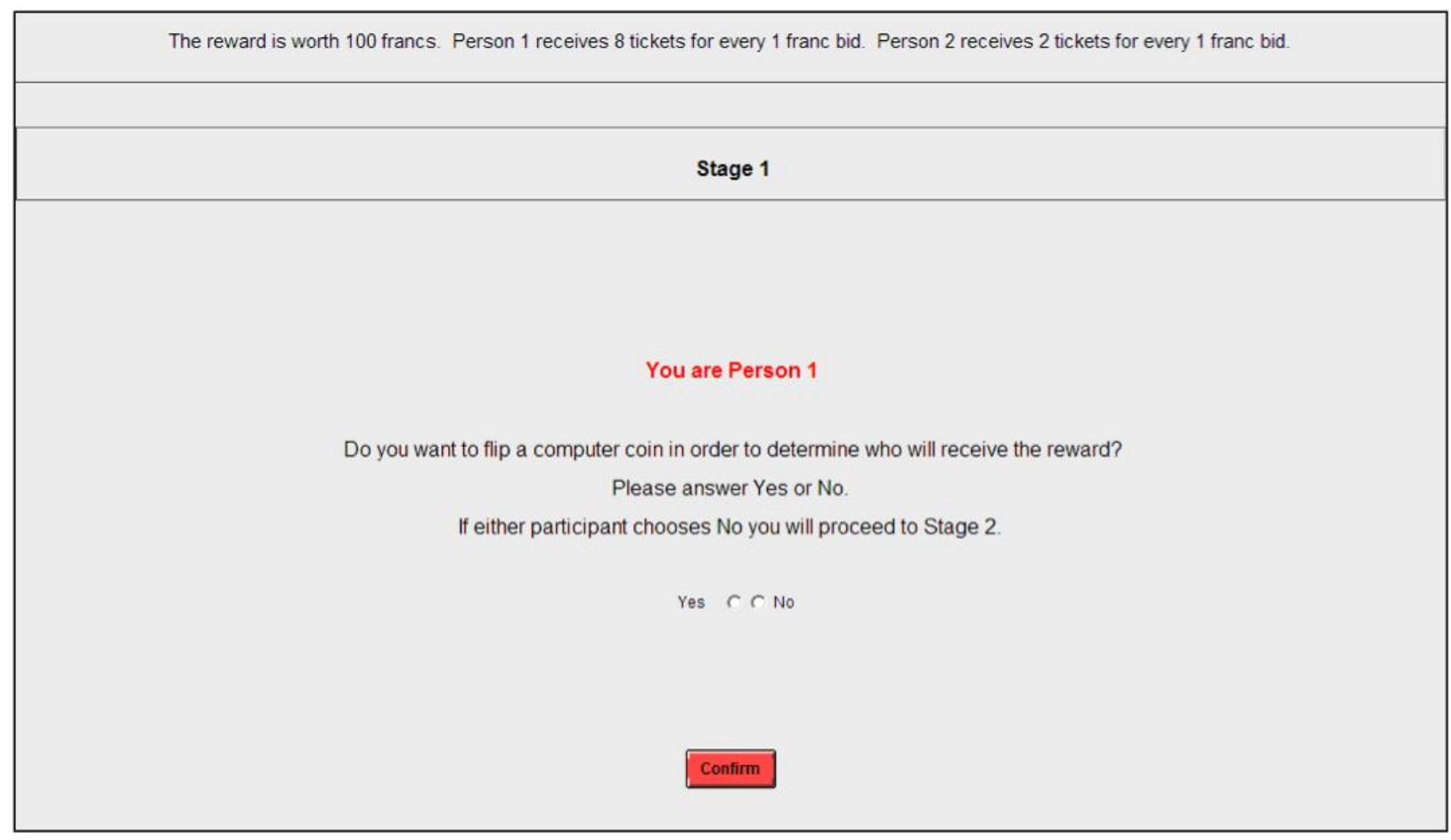

\section{EARNINGS}

If both participants choose to flip a computer coin, the round is over. The flip outcome determines who receives the reward. There is a $50 \%$ chance the coin lands heads, and $50 \%$ chance the coin lands tails. If the computer coin lands heads Person 1 receives the reward, if it lands tails, Person 2 receives the reward. So, there are two possible payoffs:

- If You Receive the Reward

$$
\text { Earnings }=100 \text { francs }
$$

- If The Other Person Receives the Reward

$$
\text { Earnings }=0 \text { francs }
$$

If you want to flip the coin, check 'Yes'. However, if either Person 1 or Person 2 chooses to not flip, by checking 'No', then both participants will enter Stage 2. At the end of the experiment we will randomly select four out of 30 periods for payment--two from the first 15 periods and two from the last 15 periods.

\section{YOUR DECISION IN STAGE 2}

If either person chooses to enter stage $\mathbf{2}$ by checking ' $\mathrm{No}^{\prime}$, each person may bid for the $\mathbf{1 0 0}$ franc reward. You may bid any integer number of francs between $\mathbf{0}$ and $\mathbf{1 0 0}$. An example of your decision screen is shown below. 


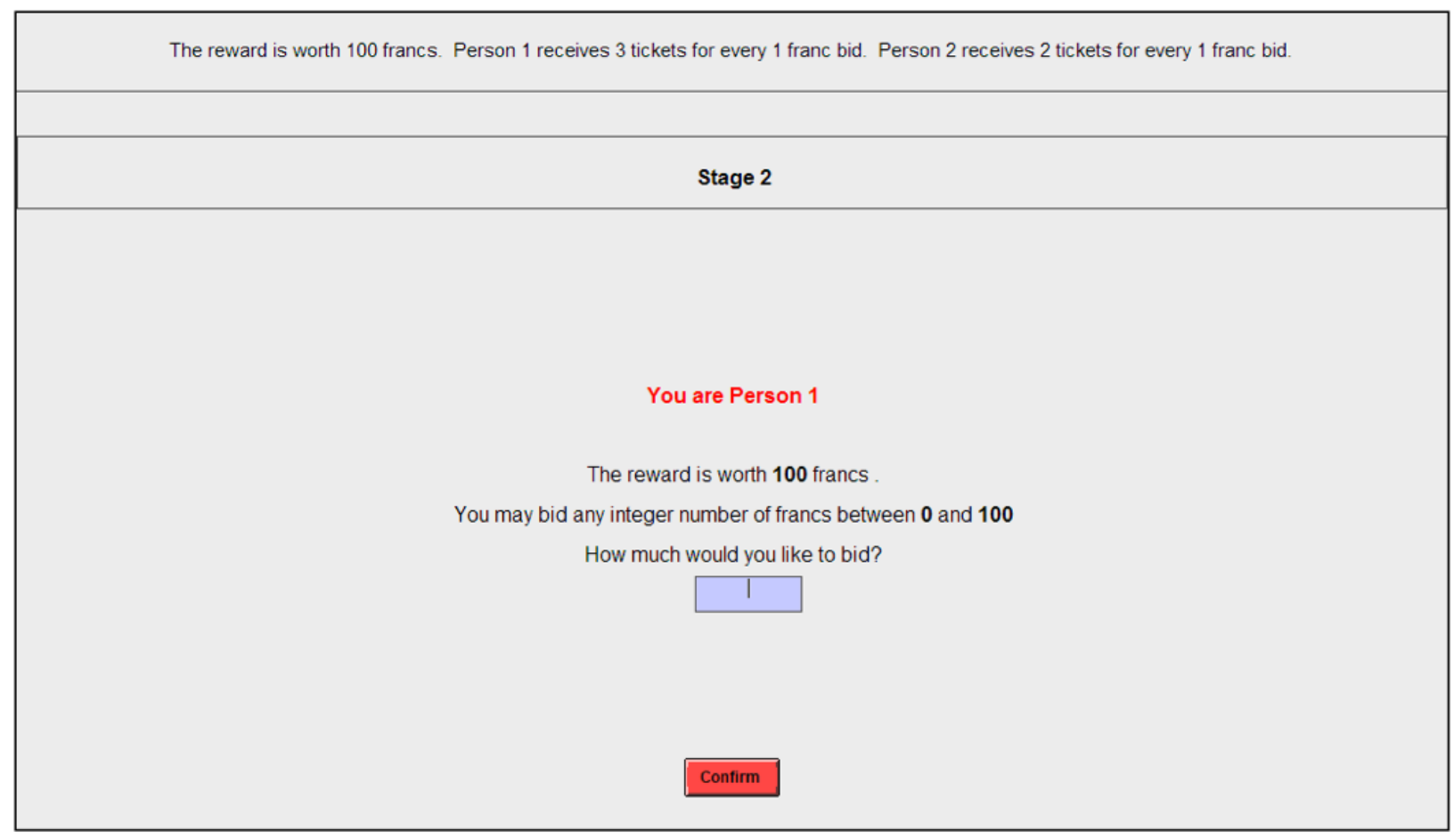

\section{EARNINGS IN STAGE 2}

After both participants make their bids, your earnings for the period are calculated. Regardless of who receives the reward, both participants will have to pay their bids. So your earnings will be calculated in the following way:

If you receive the reward:

Earnings in Stage $2=100-$ Your Bid

If you do not receive the reward:

Earnings in Stage $2=0-$ Your Bid

Remember you have already earned a $\$ 20.00$ participation fee (equivalent to 500 francs). In any period, you may receive either positive or negative earnings. At the end of the experiment we will randomly select four out of 30 periods for payment--two from the first 15 periods and two from the last 15 periods. We will sum the total earnings for these four periods and convert them to a U.S. dollar payment. If the summed earnings are negative, we will subtract them from your participation fee. If the summed earnings are positive, we will add them to your participation fee.

\section{What Does my Bid Mean?}

The more you bid, the more likely you are to receive the reward. The more the other person bids, the less likely you are to receive the reward. Specifically:

For each franc Person 1 bids Person 1 receives 8 lottery tickets

For each franc Person 2 bids Person 2 receives 2 lottery tickets

At the end of each period the computer draws randomly one ticket among all the tickets purchased by you and the other person. The owner of the winning ticket receives the reward of 100 francs. Each ticket has an equal chance of winning. So your chance of receiving the reward is given by the number of tickets you buy divided by the total number of tickets bought by you and the other person. 


$$
\text { Chance of Receiving the Reward }=\frac{\text { Your Total Lottery Tickets }}{\text { Sum of Your and Other Person's Lottery Tickets }}
$$

If both participants bid zero the reward is randomly assigned to one of the two participants.

\section{Determining Who Wins The Reward}

This is a hypothetical example used to illustrate how the computer determines who wins the reward of 100 francs. If Person 1 bids 20 francs and Person 2 bids 20 francs, then Person 1 receives 160 lottery tickets and Person 2 receives 40 lottery tickets. Then the computer randomly draws one lottery ticket out of $200(160+40)$. As you can see, Person 1 has a higher chance of receiving the reward, $0.80=$ 160/200. Person 2 has a $0.20=40 / 200$ chance of receiving the reward.

After both participants bid, the computer will make a random draw that will determine who receives the reward. Then the computer will calculate your period earnings based on your bid and whether you received the reward or not. At the end of each period, you will see:

1. Whether you chose to flip a coin and whether the other person chose to flip a coin,

2. If applicable, how much you bid and how much the other person bid,

3. Whether you received the reward or not, and

4. Your earnings for the period.

Once the outcome screen is displayed you should record your results for the period on your Personal Record Sheet under the appropriate heading. An example of the outcome screen is shown below.

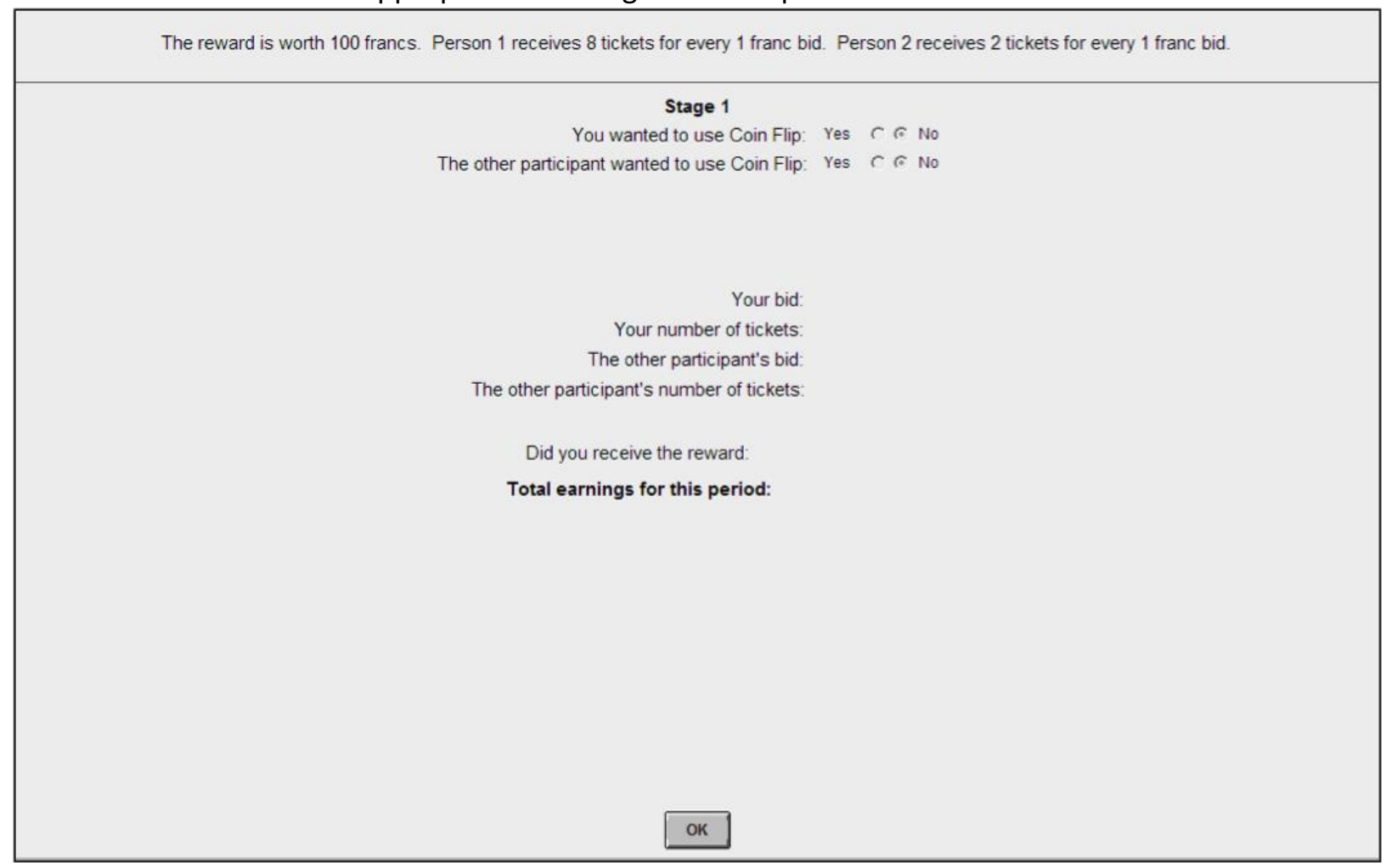

\section{IMPORTANT NOTES}

You will not be told which of the participants in this room are assigned to which two-person group. The group stays intact for 15 periods. At the end of 15 periods you will be randomly re-grouped with a 
different participant to form a new two-person group for another 15 periods. At the beginning of each period you will be told if you are Person 1 or Person 2. You will be Person 1 in half of the periods and Person 2 in half of the periods. You can never guarantee yourself the reward. If both participants choose to flip a computer coin in stage 1, then the reward is assigned randomly. If either person chooses not to flip a computer coin, then both participants proceed to stage 2 . In stage 2 , by increasing your bid you can increase your chance of receiving the reward.

\section{Quiz}

Before starting, we want you to answer some questions regarding the experiment to be sure you understand what will follow. After five minutes an experimenter will return to privately review your answers.

You will be Person 1 in how many of the periods?

You always have to bid more than zero (true or false)?

Your bid will be subtracted from your earnings (true or false)?

If both participants agree to the coin flip, what is the chance of Person 1 winning the reward?

Imagine Person 1 bids 1 franc and Person 2 bids 1 franc. What is the chance of Person 1 winning the reward?

Imagine Person 1 bids 2 francs and Person 2 bids 8 francs. What is the chance of Person 1 winning the reward?

Imagine Person 1 bids 8 francs and Person 2 bids 16 francs. What is the chance of Person 1 winning the reward?

Imagine Person 1 bids 18 francs and Person 2 bids 24 francs. What is the chance of Person 1 winning the reward?

Imagine Person 1 bids 18 francs and Person 2 bids 72 francs. What is the chance of Person 1 winning the reward?

Imagine Person 1 bids 0 francs and Person 2 bids 1 franc. What is the chance of Person 1 winning the reward?

The following instructions handed out and read aloud after subjects participated in the prior experiment.

\section{INSTRUCTIONS FOR PART II}

This part of the experiment consists of only one decision-making period and only one stage. The rules for this part are similar to the rules for part I. Francs will be converted to U.S. Dollars at a rate of $\mathbf{2 5}$ francs to 1 dollar. Participants will be randomly assigned into two-person groups. In addition to the group assignment each participant will also be randomly assigned to a specific type in the group, designated as Person 1 or Person 2.

You will bid in order to be a winner. The only difference is that in this part the winner receives a reward of zero. The reward is worth $\mathbf{0}$ francs to you and the other person in your group. After everyone have made their decisions your earnings for the period are calculated:

Earnings $=0-$ Your Bid 
The more you bid, the more likely you are to be the winner. The more the other person in your group bids, the less likely you are to be the winner. Specifically:

For each franc Person 1 bids Person 1 receives 8 lottery tickets

For each franc Person 2 bids Person 2 receives 2 lottery tickets

After both participants submit their bids, the computer draws randomly one ticket among all the tickets purchased by you and the other person. Each ticket has an equal chance of winning. So your chance of being the winner is given by the number of tickets you buy divided by the total number of tickets bought by you and the other person in your group.

Chance of Being the Winner=Your Total Lottery Tickets divided by the Sum of Your and Other Person's Lottery Tickets

If both people bid zero, the designation of winner is randomly assigned to one of the two people in the group.

After everyone has made his or her decision, you will learn whether you win or not. The computer then will display your earnings on the outcome screen. Both people will have to pay their bids. Your earnings will be converted to cash and paid at the end of the experiment. 


\section{Economic Science Institute Working Papers}

\section{1}

11-08 Brañas-Garza, P., García-Muñoz, T., and Hernan, R. Cognitive effort in the Beauty Contest Game.

11-07 Grether, D., Porter, D., and Shum, M. Intimidation or Impatience? Jump Bidding in On-line Ascending Automobile Auctions.

11-06 Rietz, T., Schniter, E., Sheremeta, R., and Shields, T. Trust, Reciprocity and Rules.

11-05 Corgnet, B., Hernan-Gonzalez, R., and Rassenti, S. Real Effort, Real Leisure and Real-time Supervision: Incentives and Peer Pressure in Virtual Organizations.

11-04 Corgnet, B. and Hernán-González R. Don’t Ask Me If You Will Not Listen: The Dilemma of Participative Decision Making.

11-03 Rietz, T., Sheremeta, R., Shields, T., Smith, V. Transparency, Efficiency and the Distribution of Economic Welfare in Pass-Through Investment Trust Games.

11-02 Corgnet, B., Kujal, P. and Porter, D. The Effect of Reliability, Content and Timing of Public Announcements on Asset Trading Behavior.

11-01 Corgnet, B., Kujal, P. and Porter, D. Reaction to Public Information in Markets: How Much Does Ambiguity Matter?

2010

10-22 Mago, S., Sheremeta, R., and Yates, A. Best-of-Three Contests: Experimental Evidence.

10-21 Kimbrough, E. and Sheremeta, R. Make Him an Offer He Can't Refuse: Avoiding Conflicts Through Side Payments.

10-20 Savikhim, A. and Sheremeta, R. Visibility of Contributions and Cost of Inflation: An Experiment on Public Goods.

10-19 Sheremeta, R. and Shields, T. Do Investors Trust or Simply Gamble?

10-18 Deck, C. and Sheremeta, R. Fight or Flight? Defending Against Sequential Attacks in the Game of Siege.

10-17 Deck, C., Lin, S. and Porter, D. Affecting Policy by Manipulating Prediction Markets: Experimental Evidence.

10-16 Deck, C. and Kimbrough, E. Can Markets Save Lives? An Experimental Investigation of a Market for Organ Donations. 
10-15 Deck, C., Lee, J. and Reyes, J. Personality and the Consistency of Risk Taking Behavior: Experimental Evidence.

10-14 Deck, C. and Nikiforakis, N. Perfect and Imperfect Real-Time Monitoring in a Minimum-Effort Game.

10-13 Deck, C. and Gu, J. Price Increasing Competition? Experimental Evidence.

10-12 Kovenock, D., Roberson, B.,and Sheremeta, R. The Attack and Defense of Weakest-Link Networks.

10-11 Wilson, B., Jaworski, T., Schurter, K. and Smyth, A. An Experimental Economic History of Whalers' Rules of Capture.

10-10 DeScioli, P. and Wilson, B. Mine and Thine: The Territorial Foundations of Human Property.

10-09 Cason, T., Masters, W. and Sheremeta, R. Entry into Winner-Take-All and Proportional-Prize Contests: An Experimental Study.

10-08 Savikhin, A. and Sheremeta, R. Simultaneous Decision-Making in Competitive and Cooperative Environments.

10-07 Chowdhury, S. and Sheremeta, R. A generalized Tullock contest.

10-06 Chowdhury, S. and Sheremeta, R. The Equivalence of Contests.

10-05 Shields, T. Do Analysts Tell the Truth? Do Shareholders Listen? An Experimental Study of Analysts' Forecasts and Shareholder Reaction.

10-04 Lin, S. and Rassenti, S. Are Under- and Over-reaction the Same Matter? A Price Inertia based Account.

10-03 Lin, S. Gradual Information Diffusion and Asset Price Momentum.

10-02 Gjerstad, S. and Smith, V. Household expenditure cycles and economic cycles, 1920 - 2010.

10-01 Dickhaut, J., Lin, S., Porter, D. and Smith, V. Durability, Re-trading and Market Performance.

2009

09-11 Hazlett, T., Porter, D., Smith, V. Radio Spectrum and the Disruptive Clarity OF Ronald Coase.

09-10 Sheremeta, R. Expenditures and Information Disclosure in Two-Stage Political Contests.

09-09 Sheremeta, R. and Zhang, J. Can Groups Solve the Problem of Over-Bidding in Contests?

09-08 Sheremeta, R. and Zhang, J. Multi-Level Trust Game with "Insider" Communication.

09-07 Price, C. and Sheremeta, R. Endowment Effects in Contests. 
09-06 Cason, T., Savikhin, A. and Sheremeta, R. Cooperation Spillovers in Coordination Games.

09-05 Sheremeta, R. Contest Design: An Experimental Investigation.

09-04 Sheremeta, R. Experimental Comparison of Multi-Stage and One-Stage Contests.

09-03 Smith, A., Skarbek, D., and Wilson, B. Anarchy, Groups, and Conflict: An Experiment on the Emergence of Protective Associations.

09-02 Jaworski, T. and Wilson, B. Go West Young Man: Self-selection and Endogenous Property Rights.

09-01 Gjerstad, S. Housing Market Price Tier Movements in an Expansion and Collapse.

2008

08-10 Dickhaut, J., Houser, D., Aimone, J., Tila, D. and Johnson, C. High Stakes Behavior with Low Payoffs: Inducing Preferences with Holt-Laury Gambles.

08-09 Stecher, J., Shields, T. and Dickhaut, J. Generating Ambiguity in the Laboratory.

08-08 Stecher, J., Lunawat, R., Pronin, K. and Dickhaut, J. Decision Making and Trade without Probabilities.

08-07 Dickhaut, J., Lungu, O., Smith, V., Xin, B. and Rustichini, A. A Neuronal Mechanism of Choice.

08-06 Anctil, R., Dickhaut, J., Johnson, K., and Kanodia, C. Does Information Transparency Decrease Coordination Failure?

08-05 Tila, D. and Porter, D. Group Prediction in Information Markets With and Without Trading Information and Price Manipulation Incentives.

08-04 Caginalp, G., Hao, L., Porter, D. and Smith, V. Asset Market Reactions to News: An Experimental Study.

08-03 Thomas, C. and Wilson, B. Horizontal Product Differentiation in Auctions and Multilateral Negotiations.

08-02 Oprea, R., Wilson, B. and Zillante, A. War of Attrition: Evidence from a Laboratory Experiment on Market Exit.

08-01 Oprea, R., Porter, D., Hibbert, C., Hanson, R. and Tila, D. Can Manipulators Mislead Prediction Market Observers? 